\title{
Giuseppe Martoccia, Hérodiade, Scène
}

\section{Alessandra Marangoni}

\section{(2) OpenEdition}

\section{Journals}

\section{Edizione digitale}

URL: http://journals.openedition.org/studifrancesi/6995

DOI: $10.4000 /$ studifrancesi.6995

ISSN: 2427-5856

\section{Editore}

Rosenberg \& Sellier

\section{Edizione cartacea}

Data di pubblicazione: 1 septembre 2010

Paginazione: 397

ISSN: 0039-2944

\section{Notizia bibliografica digitale}

Alessandra Marangoni, «Giuseppe Martoccia, Hérodiade, Scène», Studi Francesi [Online], 161 (LIV | II) |

2010, online dal 30 novembre 2015, consultato il 12 janvier 2021. URL: http://

journals.openedition.org/studifrancesi/6995 ; DOI: https://doi.org/10.4000/studifrancesi.6995

Questo documento è stato generato automaticamente il 12 janvier 2021.

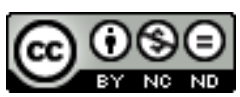

Studi Francesi è distribuita con Licenza Creative Commons Attribuzione - Non commerciale - Non opere derivate 4.0 Internazionale. 


\title{
Giuseppe Martoccia, Hérodiade, Scène
}

\author{
Alessandra Marangoni
}

\section{NOTIZIA}

GIUSEPPE MARTOCCIA, Hérodiade, Scène, Roma, Aracne, 2007, pp. 164.

1 Questo studio rigoroso, che segnaliamo con lieve ritardo, costituisce un utilissimo strumento per affrontare Hérodiade, Scène: unico frammento di Hérodiade pubblicato da Mallarmé e punto di partenza per le successive riprese di Hérodiade da parte del poeta.

2 Viene dapprima seguita, tramite la corrispondenza, la tormentata genesi dell'opera (pubblicata sul Parnasse Contemporain del 1871) scrutando la quale, come è noto, Mallarmé andrà incontro alla grande crisi metafisica della sua esistenza, fino ad esperire il Nulla (è la celebre lettera a Cazalis dell'aprile 1866). Due dati vengono sempre tenuti presenti: l'alternanza, e quasi la complementarietà nella genesi, tra Hérodiade "poème hivernal» e il Faune "poème estival», nonché la primitiva destinazione teatrale di Hérodiade (come del resto del Monologue d'un faune) inizialmente scritto per il Théâtre Français.

3 Viene poi analizzato il testo di questi 134 versi alessandrini, di cui si danno anche le numerose varianti. Colpisce la concisa precisione con cui vengono via via considerate e citate anche le moltissime letture anteriori. Cosicché, nel breve spazio di questo libro, si racchiude un considerevole patrimonio di informazioni bibliografiche (come si evince anche dall'imponente bibliografia cronologica). Non mancano interpretazioni originali su singoli punti, ad esempio sul ruolo niente affatto secondario della nutrice. Si fa soprattutto strada un convincente accostamento a Phèdre I, 3 di cui Hérodiade, Scène, opera nata per il teatro, sarebbe riscrittura invero splendida. 